\title{
Obituary Notices
}

\section{Prof. J. B. Senderens}

$\mathrm{T}^{\mathrm{H}}$ HE death on September 26 of Jean Baptiste Senderens, who was born in the village of Barbachen in the Hautes-Pyrénées in 1856, removes from our midst one of the most active workers in the field of contact catalysis.

Together with Sabatier in 1899, Senderens found that finely divided nickel could be employed as a catalyst for the hydrogenation of the vapours of a variety of organic substances, and with this discovery the intrusion of catalytic methods into technical organic chemistry may be said to have commenced. In fact, the first patent for the reduction of an organic substance by hydrogen in the presence of catalytic metals was granted to Senderens (D.R.P., 139, 457, of July 26, 1901) for the production of aniline from nitrobenzene. It is possible that the achievements of Senderens would have left an even deeper imprint on modern chemical industry if he had not confined himself to reactions in the vapour phase and left the treatment of liquids, for example, modern fat hardening, coal and liquid tar hydrogenation, to others. Nevertheless, his technical contributions, especially in the field of fine chemicals, and in association with the firm of Poulenc Frères, are important and varied enough to leave industry permanently indebted to him.

One has only to glance at any text-book on contact catalysis to obtain some idea of the wide diversity of the applications that Senderens made of this new method of contact catalysis in the field of organic chemistry. The preparation of substances such as ketones from acids or of cyclohexane from benzene are indeed too numerous to mention. In respect to the theory of contact catalysis, Senderens was a protagonist of the view that intermediate compounds were formed between reactant and substrate-in more modern terminology, that chemisorption was a pre-requisite for chemical reaction. It may be noted that, in addition to the purely preparational character of his work, he made a number of very significant observations which must eventually find their place when we are in possession of the detailed mechanism of these surface reactions. Thus he noted that whilst benzene could be hydrogenated to cyclohexane, dehydrogenation could be effected at higher temperatures. Thus equilibrium can be obtained from both ends and permits of the accurate evaluation of the free energy changes involved in organic reactions. His work on this reaction renders Senderens a pioneer in what is now an important field of physical chemistry.

Again, Senderens observed that acetylene could be hydrogenated to ethane without the addition of hydrogen, the latter being supplied by simultaneous dehydrogenation of part of the acetylene; this reaction may be regarded as the prototype of important reactions involved in the oil industry, where the fundamental processes consist in the catalytic making and breaking of carbon-carbon and carbon-hydrogen bonds. He noted that nickel was a 'better' hydrogenating catalyst than copper; thus carbon dioxide can readily be converted to methane on the former but only to carbon monoxide on the latter metal ; likewise amyl acetylene is converted to heptane on nickel but only to amyl ethylene on copper. Similarly, he pointed out that whilst an active nickel catalyst will hydrogenate both cresol and phenol, a nickel catalyst that had been employed for a long period in hydrogenating phenol was rendered inert for the cresol reaction. Here we are evidently dealing with cases of specificity, one of the most fascinating and mysterious features of contact catalysis.

Senderens' work was not confined to hydrogenation processes; he examined numerous cases of dehydrations, that of alcohol to ether or ethylene being the most important. Finally, we may mention that he initiated investigations in the much more difficult field of catalytic oxidations ; for example, isoamyl alcohol to aldehyde and the preparation of benzoic acid from toluene.

Senderens, like several well-known French scientific workers, was a faithful son of the Church, becoming first an Abbé and later a Canon. Together with Sabatier he was made an honorary fellow of the Chemical Society in March 1920, and he was elected correspondant of the Paris Academy of Sciences in 1922.

In Grignard's "Traité de Chimie Organique" (Vol. 3, 941; 1936) there is written : "La catalyse n'a pris de l'importance en chimie organique que per les travaux de Sabatier et Senderens" (1897-1905), a statement which cannot fail to find universal acceptance.

F. K. RIDEAL.

\section{Dr. R. O. Hall}

WE regret to announce the death on November 28. as the result of an accident, of Robert Oswald Hall,

Hall was born on June 24, 1905, and educated at Wakefield Grammar School from 1916 until 1923. In 1924 he entered the University of Leeds, where he took the honours chemistry course, holding the Lord Kitchener National Memorial scholarship from 1925 until 1929. Later, he took part in a general study of the hygienic properties of clothing, and investigated the laws governing the transmission of water vapour through textile fabrics as a function of their structure and the nature of the component fibres. An account of the work is to be found in the thesis on "The Ventilating Properties of Textile Materials and Fabrics", for which he was awarded the degree of Ph.D. of the University of Leeds in 1930. In the same year, he was elected an associate of the Institute of Chemistry, and was appointed an assistant chemist in the Government Laboratory. 